\title{
Experimental and numerical analysis of the fracture response of alkali-activated slag-based materials
}

\author{
Martin Lipowczan ${ }^{1, *}$, David Lehký $^{1}$, Hana Šimonová ${ }^{1}$, and Barbara Kucharczyková ${ }^{1}$ \\ ${ }^{1}$ Brno University of Technology, Faculty of Civil Engineering, Veveři 331/95, 60200 Brno, Czech \\ Republic
}

\begin{abstract}
The paper deals with the experimental and numerical determination of mechanical fracture parameters of fine-grained composites based on the alkali-activated slag (AAS) at different ages of hardening. Two AAS composites, which differed only in the presence of shrinkage reducing admixture, were studied. The prismatic specimens with the nominal dimensions of $40 \times 40 \times 160 \mathrm{~mm}$ and initial central edge notch were subjected to fracture tests in a three-point bending configuration. The results of the fracture tests in the form load $F$ versus deflection $d$ diagrams were used as input data for the identification of parameters via the inverse analysis based on the artificial neural network whose aim is to transfer the fracture test response data to the desired material parameters. The modulus of elasticity, tensile strength, and fracture energy values were identified and subsequently compared with values obtained based on the direct fracture test evaluation using the effective crack model and work-of-fracture method.
\end{abstract}

\section{Introduction}

When modelling structures composed of quasi-brittle materials using non-linear fracture mechanics, one of the essential steps is to determine the values of material parameters, especially mechanical fracture parameters. Other reasons include assessing the quality of existing materials or the analysis of the behaviour of newly developed materials. In many cases, the attention is paid to the resistance to crack initiation and propagation, rather than the maximum strength of the material. One venue for obtaining mechanical fracture parameters is to do it indirectly - based on a combination of fracture tests and inverse analysis $[1,2]$. This paper presents a methodology for the determination of mechanical fracture parameters of fine-grained composites. Experimental data from three-point bending tests are used in the artificial neural network-based (ANN) inverse analysis method [3].

In order to make the identification procedure user-friendly, the inverse methods were implemented in the FraMePID-3PB software tool [4]. This software was designed to identify the values of material parameters for standard concrete. Notched prism specimens with the nominal dimensions of $100 \times 100 \times 400 \mathrm{~mm}$ and tested in a three-point bending (3PB) test configuration were utilized. At present, the method and identification software were extended

\footnotetext{
* Corresponding author: lipowczan.m@fce.vutbr.cz
} 
in order to identify mechanical fracture parameters of fine-grained brittle matrix composites typically tested using smaller specimens with the nominal dimensions of $40 \times 40 \times 160 \mathrm{~mm}$. Due to the large variability of material properties of studied fine-grained composites, an updated inverse analysis method based on a neural networks ensemble was developed [5].

The aim of the paper is to present the application of the updated inverse analysis method to selected specimens made of fine-grained composites and to compare the obtained results with values obtained from the direct fracture test evaluation using the effective crack model [6] and the work-of-fracture method [7]. Experimental and numerical determination of mechanical fracture parameters was performed for fine-grained composites based on the alkali-activated slag matrix (AAS) at different ages of hardening (3 days, 28 days, 90 days and 2 years).

\section{Mixtures and specimens}

The primary aim of the performed experimental investigation was to verify the effect of the shrinkage reducing admixture (SRA) on the overall progress of length changes and mechanical fracture parameters during AAS composites ageing. Therefore, the two AAS fine-grained composites, which differed only in the presence of the SRA, were studied. The sets of specimens were labelled as follows: VIII and IX, specimens without and with the SRA, respectively. The composites were prepared using ground granulated blast furnace slag which was activated by water glass with the silicate modulus of 2.0, standardized CEN siliceous sand with the particle grain size distribution of 0-2 mm, and water. Commercially produced SRA was added into the second mixture in the amount of $2 \%$ by weight of slag. To highlight the influence of the SRA, all of the test specimens were not protected from drying during the whole time of ageing and were stored in laboratory at the ambient temperature of $21 \pm 2{ }^{\circ} \mathrm{C}$ and relative humidity of $60 \pm 10 \%$. Two sets of test specimens with the dimensions of $40 \times 40 \times 160 \mathrm{~mm}$, which differed in the process of manufacturing, were prepared from both composites and tested at particular ages. The first set contained prismatic specimens manufactured in the moulds with the nominal dimensions of $40 \times 40 \times 160 \mathrm{~mm}$ and tested at the age of 3,28, 90 days and 2 years. Another set of test specimens moulded into the moulds with the dimensions of $100 \times 60 \times 1000 \mathrm{~mm}$ was manufactured and cured for 90 days in laboratory. The second set of specimens was manufactured by cutting these specimens to the test specimens with the nominal dimensions of $40 \times 40 \times 160 \mathrm{~mm}$. The specimens obtained in this manner were designated as "cut" and were tested at the age of 90 days and 2 years. An initial central edge notch was cut in all of the test specimens before the start of particular fracture tests, see Figure 1.
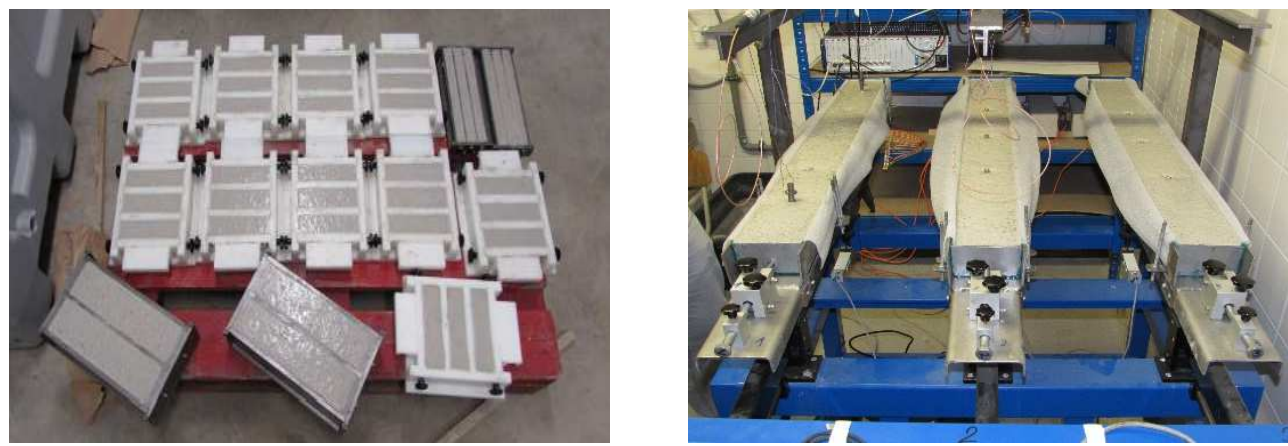

Fig. 1. Two ways of specimen preparation - specimens casted into small polypropylene moulds (left) and specimens cut from large bodies (right). 


\section{Material parameters determination}

\subsection{Fracture tests}

As mentioned above, 3PB fracture tests of prismatic specimens were carried out. The distance of supports was $120 \mathrm{~mm}$. In the centre of each specimen a notch was cut to a depth of about $1 / 3$ of the specimen depth. Tests were performed in a mechanical testing machine which was sufficiently stiff to ensure stable test progress. The loading was performed with the constant increment of displacement which was set to $0.02 \mathrm{~mm} / \mathrm{min}$. The outcome of each test was the force-deflection diagram ( $F-d$ diagram), which was subsequently used for mechanical fracture parameter determination. A total of seventy-two 3PB tests of specimens VIII and IX were carried out, from which 48 were the specimens prepared by moulding and 24 were specimens prepared by cutting. Six specimens were tested from each set and at a specific age. The resulting $F-d$ diagrams are depicted in Figure 2.
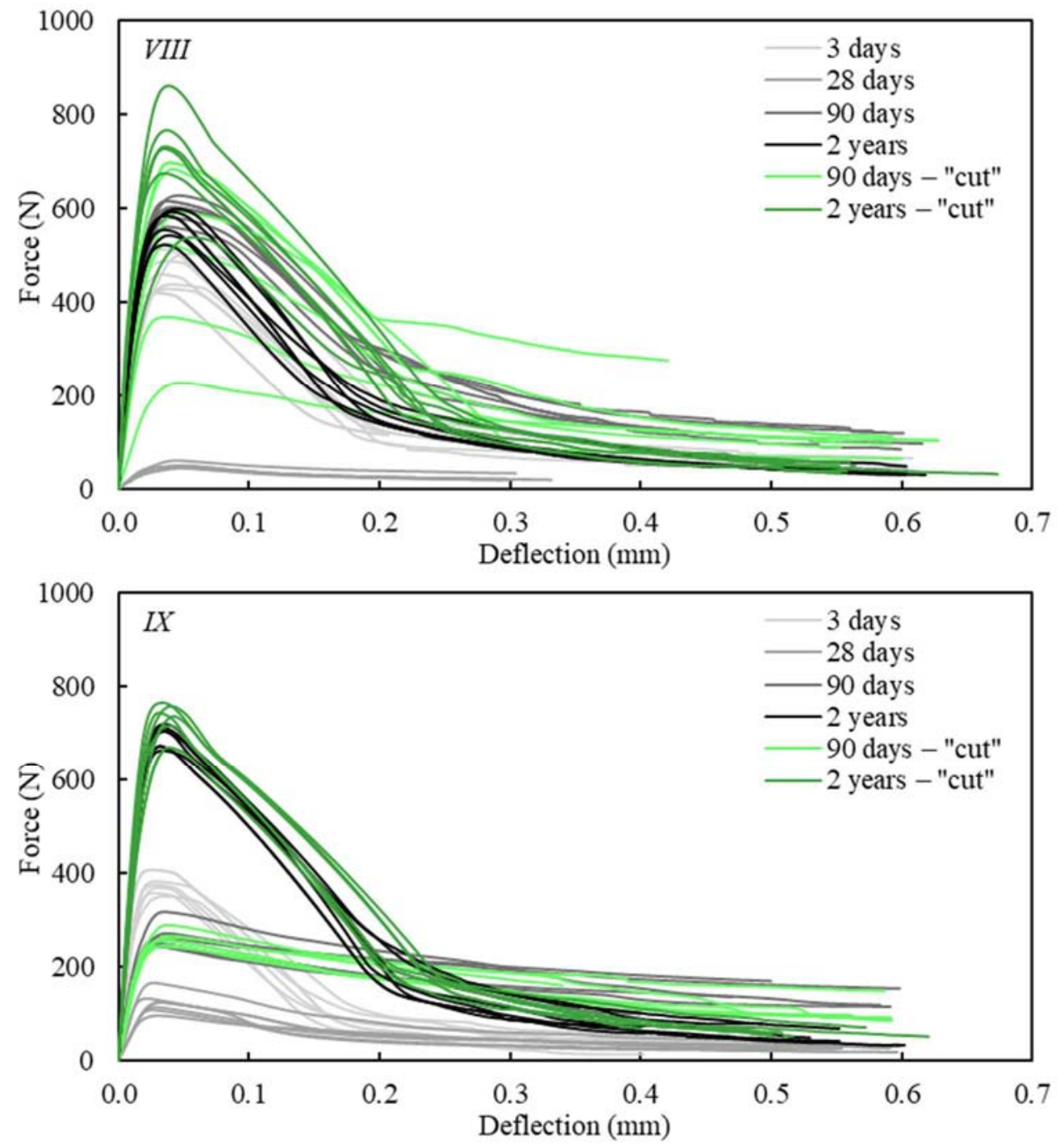

Fig. 2. $F-d$ diagrams obtained from 3 PB tests of specimens without the SRA (top) and with the SRA (bottom). 


\subsection{ANN-based inverse analysis}

The inverse procedure based on artificial intelligence developed by Novák and Lehký [3] utilizes the transformation of the fracture test response data into the required mechanical fracture parameters: $\mathbf{R} \rightarrow \mathbf{P}$. This method is based on the comparison of laboratory measurements with the results obtained by numerical simulation of the same test. ANN serves here as a surrogate model of the unknown inverse function describing the relationship between mechanical fracture input parameters and corresponding response parameters:

$$
\mathbf{P}=f_{\mathrm{ANN}}^{-1}(\mathbf{R}) \text {. }
$$

The computational model describing the 3PB test was created in ATENA finite element method (FEM) software [8], see Figure 3. The 3D Non-Linear Cementitious 2 material model was used. The compression behaviour is described by Menétrey-Willam yield surface with hardening and softening phases [9] and the tensile behaviour is governed by the Rankinetype criterion with exponential softening according to Hordijk [10].

By means of sensitivity analysis, those mechanical fracture parameters of the material model were selected, which have the greatest influence on the behaviour of fine-grained composites during the fracture tests. These were the modulus of elasticity $E_{\mathrm{c}, \mathrm{ID}}$, tensile strength $f_{\mathrm{t}, \mathrm{ID}}$ and specific fracture energy $G_{\mathrm{F}, \mathrm{ID}}$. Other parameters were less important.

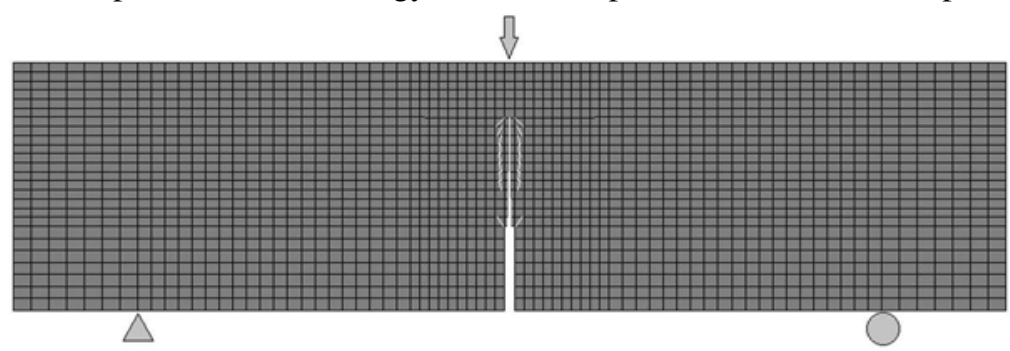

Fig. 3. FEM model of the three-point bending test adopted for numerical simulations.

\subsection{A neural network ensemble}

The apparent large variability of responses obtained from the 3PB tests of fine-grained composites does not allow the application of one robust neural network to identify mechanical fracture parameters. Therefore, an identification method based on an ensemble of neural networks was developed. Such a system allows to identify parameters of a wide range of different compositions with good accuracy.

The identified fracture parameters - modulus of elasticity, tensile strength and specific fracture energy - form a three-dimensional space. This 3D space is systematically divided into multiple subspaces that overlap each other. This eliminates the dead spots on the border between the two subspaces. Figure 4 shows active regions used to identify the fracture parameters of samples VIII and IX. Each subspace contains one ANN trained for a specified range of identified parameters in the subspace. The advantage of this system is that it can be easily extended to cover missing sub-regions without affecting existing subspaces.

For the selected fracture parameters, it is necessary to compile a stochastic model, i.e. to define the statistical moments and the respective probability distribution. Values in the stochastic model vary depending on the subspace of the identified parameters. Rectangular distribution was used for the random variables of the modulus of elasticity and tensile strength. The specific fracture energy is described by the descending trapezoidal distribution. The benefit of this distribution is the concentration of lower values of the specific fracture energy, thus refining the inverse analysis. 

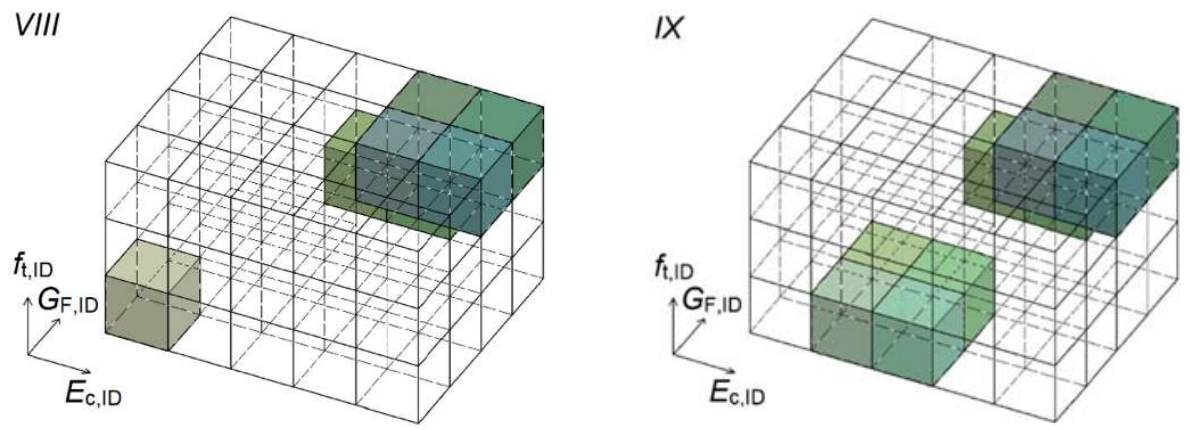

Fig. 4. 3D space of fracture parameters with active subspaces, which were used to identify the parameters of specimens VIII (left) and IX (right).

The next step is the randomization of identified parameters and a repeated calculation of the deterministic computational model in ATENA software. The number of FEM model simulations is dependent on the size of a given region of identified parameters. For smaller subspaces, 50 simulations are sufficient, while for larger subspaces 100 simulations were used. For each FEM model simulation, a response in the form of $F-d$ diagram is obtained from which the response parameters are determined. Response parameters together with random realization of material parameters form a training set for the neural network.

The last step is the creation and training of the ANNs. A feed-forward multi-layered network of the following structure is utilized: 3 inputs, 1 hidden layer having 6 neurons with a nonlinear transfer function (hyperbolic tangent), and 1 output layer having 3 neurons with a linear transfer function, see Figure 5.

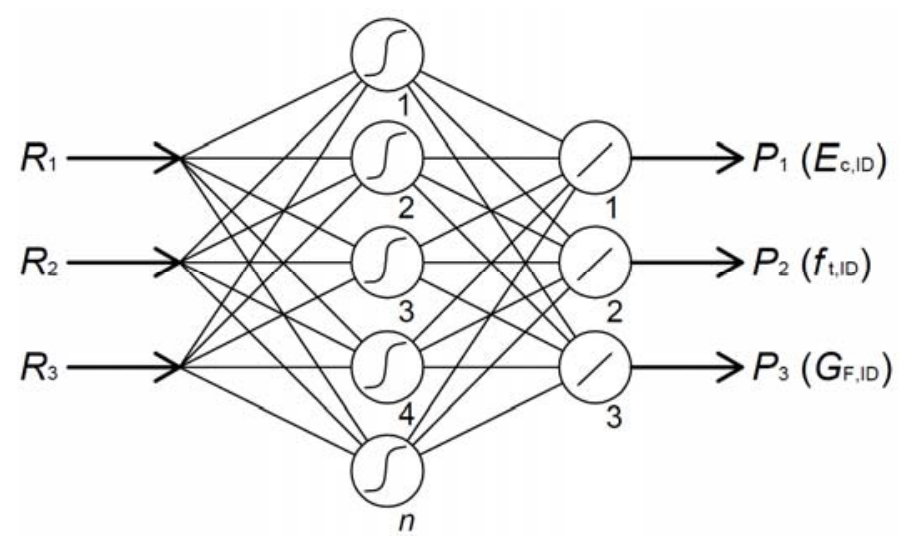

Fig. 5. Diagram of the structure of the utilized feed-forward multilayer network.

A suitable subspace for the analysed specimen is automatically selected based on an initial analysis of the experimental response data and the corresponding ANN is activated. The set of mechanical fracture parameters is calculated by simulating the ANN with obtained response parameters. There may be cases where we obtain material parameter values from multiple active networks. The values of these parameters are in an area in which multiple subspaces overlap. In this case, we calculate a weighted average from these values, taking into account the distance of the obtained parameter values from the centre and boundary of the subregion. See more detailed description in [5]. 


\subsection{Effective Crack Length Method, Work-of-Fracture Method}

After the appropriate processing of measured diagrams, the ascending parts of $F-d$ diagrams were used to estimate the modulus of elasticity $E_{\mathrm{c}}$ values according to [6].

After that, the effective fracture toughness $K_{\text {Ice }}$ was determined based on the $F-d$ diagrams using the effective crack model [6]. The effective crack length $a_{\mathrm{e}}$ corresponding with the maximum load $F_{\max }$ and midspan deflection $d_{F \max }$, had to be calculated first. Subsequently, the $K_{\text {Ice }}$ was calculated using the linear elastic fracture mechanics formula according to [6].

The complete $F-d$ diagrams, including their post-peak parts, were employed to determine the work of fracture $W_{\mathrm{F}}{ }^{*}$ value, which is given by the area under the $F-d$ diagram. After that, the specific fracture energy $G_{\mathrm{F}}{ }^{*}$ values were determined according to the RILEM method [7]. The work of fracture value was divided by the area of a ligament (cross-section of specimens through which the crack grows).

\section{Results}

The values of mechanical fracture parameters of the studied fine-grained composites identified using the ANN-based inverse analysis method are shown in Table 1. Identification was performed for all 72 AAS specimens without (VIII) and with the SRA (IX), prepared by moulding and cutting. Table 2 shows the results of the direct evaluation of parameters from experimentally obtained $F-d$ diagrams by the effective crack model and the work-of-fracture method.

Table 1. Mean values (CoV in \%) of selected mechanical fracture parameters of the studied composites tested at different ages of hardening - identification using ensemble of neural networks.

\begin{tabular}{|c|c|c|c|c|c|c|c|c|}
\hline \multirow[b]{2}{*}{ Parameter } & \multirow[b]{2}{*}{ Unit } & \multirow[b]{2}{*}{ Set } & \multicolumn{6}{|c|}{ Age of specimens } \\
\hline & & & 3 days & 28 days & 90 days & $\begin{array}{c}90 \text { days } \\
\text { (cut) }\end{array}$ & 2 years & $\begin{array}{c}2 \text { years } \\
\text { (cut) }\end{array}$ \\
\hline \multirow[t]{2}{*}{$E_{\mathrm{c}, \mathrm{ID}}$} & $\mathrm{GPa}$ & VIII & $\begin{array}{c}12.7 \\
(13.5)\end{array}$ & $\begin{array}{c}0.9 \\
(9.4)\end{array}$ & $\begin{array}{l}14.7 \\
(4.8)\end{array}$ & $\begin{array}{c}11.5 \\
(42.1)\end{array}$ & $\begin{array}{l}15.6 \\
(4.0)\end{array}$ & $\begin{array}{c}19.4 \\
(23.7)\end{array}$ \\
\hline & & IX & $\begin{array}{c}12.4 \\
(16.1)\end{array}$ & $\begin{array}{c}3.1 \\
(24.5)\end{array}$ & $\begin{array}{c}7.3 \\
(11.1)\end{array}$ & $\begin{array}{c}6.8 \\
(4.2)\end{array}$ & $\begin{array}{l}16.8 \\
(6.3)\end{array}$ & $\begin{array}{c}17.3 \\
(14.4)\end{array}$ \\
\hline \multirow[t]{2}{*}{$f_{\mathrm{t}, \mathrm{ID}}$} & $\mathrm{MPa}$ & VIII & $\begin{array}{c}1.43 \\
(10.7)\end{array}$ & $\begin{array}{c}0.16 \\
(11.3)\end{array}$ & $\begin{array}{l}1.73 \\
(4.1)\end{array}$ & $\begin{array}{c}1.48 \\
(36.3)\end{array}$ & $\begin{array}{l}1.76 \\
(5.4)\end{array}$ & $\begin{array}{c}2.14 \\
(15.7)\end{array}$ \\
\hline & & IX & $\begin{array}{l}1.16 \\
(7.4)\end{array}$ & $\begin{array}{c}0.39 \\
(20.1)\end{array}$ & $\begin{array}{c}0.69 \\
(12.1)\end{array}$ & $\begin{array}{l}0.69 \\
(7.1)\end{array}$ & $\begin{array}{l}2.18 \\
(6.3)\end{array}$ & $\begin{array}{l}2.27 \\
(3.8)\end{array}$ \\
\hline \multirow[t]{2}{*}{$G_{\mathrm{F}, \mathrm{ID}}$} & $\mathrm{J} / \mathrm{m}^{2}$ & VIII & $\begin{array}{l}105.6 \\
(19.5)\end{array}$ & $\begin{array}{c}14.8 \\
(25.3)\end{array}$ & $\begin{array}{l}201.0 \\
(6.8)\end{array}$ & $\begin{array}{l}199.1 \\
(31.0)\end{array}$ & $\begin{array}{l}119.5 \\
(12.1)\end{array}$ & $\begin{array}{l}187.1 \\
(13.7)\end{array}$ \\
\hline & & IX & $\begin{array}{c}65.3 \\
(18.4)\end{array}$ & $\begin{array}{c}31.8 \\
(30.9)\end{array}$ & $\begin{array}{l}163.6 \\
(20.8)\end{array}$ & $\begin{array}{l}149.9 \\
(15.4)\end{array}$ & $\begin{array}{c}163.3 \\
(9.9)\end{array}$ & $\begin{array}{l}181.9 \\
(12.6)\end{array}$ \\
\hline
\end{tabular}

Based on the results, it can be stated that the modulus of elasticity values obtained by the identification using the ensemble of neural networks are the same compared to the values obtained by the direct evaluation for all of the tested sets of specimens independently from the materials composition or process of manufacturing of test specimens. Concerning the absolute values of fracture energy, it can be stated that the absolute values of this parameter differ substantially depending on the method of evaluation. The numerical identification using the ANN provides higher values of fracture energy compared to the values obtained by direct methods of fracture test evaluation for all sets of test specimens. The variability of results obtained by direct methods does not differ from that obtained by identification (except for the set of IX specimens at 90 days of age). The differences in mean values of fracture energy correspond to their different physical meanings - the identified values are primarily related to the material point, whereas the values obtained from the work-of-fracture method 
are related to the tested specimen, the size and shape of fracture process zone and represent the average fracture energy.

Table 2. Mean values ( $\mathrm{CoV}$ in \%) of selected mechanical fracture parameters of the studied composites tested at different ages of hardening - effective crack length method and work-of-fracture method.

\begin{tabular}{|c|c|c|c|c|c|c|c|c|}
\hline \multirow[b]{2}{*}{ Parameter } & \multirow[b]{2}{*}{ Unit } & \multirow[b]{2}{*}{ Set } & \multicolumn{6}{|c|}{ Age of specimens } \\
\hline & & & 3 days & 28 days & 90 days & $\begin{array}{c}90 \text { days } \\
\text { (cut) }\end{array}$ & 2 years & $\begin{array}{l}2 \text { years } \\
\text { (cut) }\end{array}$ \\
\hline \multirow[t]{2}{*}{$\overline{E_{\mathrm{c}}}$} & $\mathrm{GPa}$ & VIII & $\begin{array}{c}12.0 \\
(15.4)\end{array}$ & $\begin{array}{c}0.9 \\
(13.0)\end{array}$ & $\begin{array}{l}14.3 \\
(5.3)\end{array}$ & $\begin{array}{c}12.7 \\
(22.3)\end{array}$ & $\begin{array}{l}14.1 \\
(5.1)\end{array}$ & $\begin{array}{l}17.8 \\
(6.6)\end{array}$ \\
\hline & & IX & $\begin{array}{c}11.6 \\
(13.9)\end{array}$ & $\begin{array}{c}3.1 \\
(29.0)\end{array}$ & $\begin{array}{c}6.9 \\
(8.0)\end{array}$ & $\begin{array}{c}6.1 \\
(5.8)\end{array}$ & $\begin{array}{l}16.2 \\
(3.8)\end{array}$ & $\begin{array}{c}16.5 \\
(10.6)\end{array}$ \\
\hline \multirow[t]{2}{*}{$K_{\text {Ice }}$} & $\mathrm{MPa} \cdot \mathrm{m}^{1 / 2}$ & VIII & $\begin{array}{l}0.541 \\
(12.1)\end{array}$ & $\begin{array}{c}0.052 \\
(9.2)\end{array}$ & $\begin{array}{l}0.717 \\
(10.2)\end{array}$ & $\begin{array}{l}0.643 \\
(25.1)\end{array}$ & $\begin{array}{l}0.678 \\
(11.5)\end{array}$ & $\begin{array}{l}0.790 \\
(10.6)\end{array}$ \\
\hline & & IX & $\begin{array}{l}0.418 \\
(7.4)\end{array}$ & $\begin{array}{l}0.108 \\
(20.2)\end{array}$ & $\begin{array}{l}0.279 \\
(12.3)\end{array}$ & $\begin{array}{c}0.283 \\
(6.5)\end{array}$ & $\begin{array}{c}0.696 \\
(5.7)\end{array}$ & $\begin{array}{c}0.778 \\
(7.1)\end{array}$ \\
\hline \multirow[t]{2}{*}{$\boldsymbol{G}_{\mathbf{F}}{ }^{*}$} & $\mathrm{~J} / \mathrm{m}^{2}$ & VIII & $\begin{array}{c}69.7 \\
(19.2)\end{array}$ & $\begin{array}{c}5.4 \\
(7.2)\end{array}$ & $\begin{array}{l}116.4 \\
(7.3)\end{array}$ & $\begin{array}{l}114.4 \\
(2.5)\end{array}$ & $\begin{array}{l}94.3 \\
(8.7)\end{array}$ & $\begin{array}{l}130.9 \\
(14.8)\end{array}$ \\
\hline & & IX & $\begin{array}{l}47.6 \\
(9.3)\end{array}$ & $\begin{array}{c}18.3 \\
(23.4)\end{array}$ & $\begin{array}{c}52.0 \\
(38.3)\end{array}$ & $\begin{array}{c}77.7 \\
(43.0)\end{array}$ & $\begin{array}{l}118.4 \\
(5.6)\end{array}$ & $\begin{array}{l}129.4 \\
(7.4)\end{array}$ \\
\hline
\end{tabular}

For the verification of the proposed identification system and the obtained mechanical fracture parameters, one specimen from each set was selected and its response was numerically simulated. The resulting $F-d$ diagrams obtained by FEM analyses with material inputs based on identified parameters were compared with diagrams acquired from experiments performed for all sets of specimens. Good convergence was achieved between the numerically and experimentally obtained $F-d$ diagrams approximately up to the deflection of $0.20 \mathrm{~mm}$, see Figure 6 and 7. Experimentally obtained $F-d$ diagrams are depicted in colour according to the respective set of specimens in Figure 2 . The $F-d$ diagrams from numerical simulations of the computational model have colours according to the respective active subspace (see Figure 4) utilized for identification. 


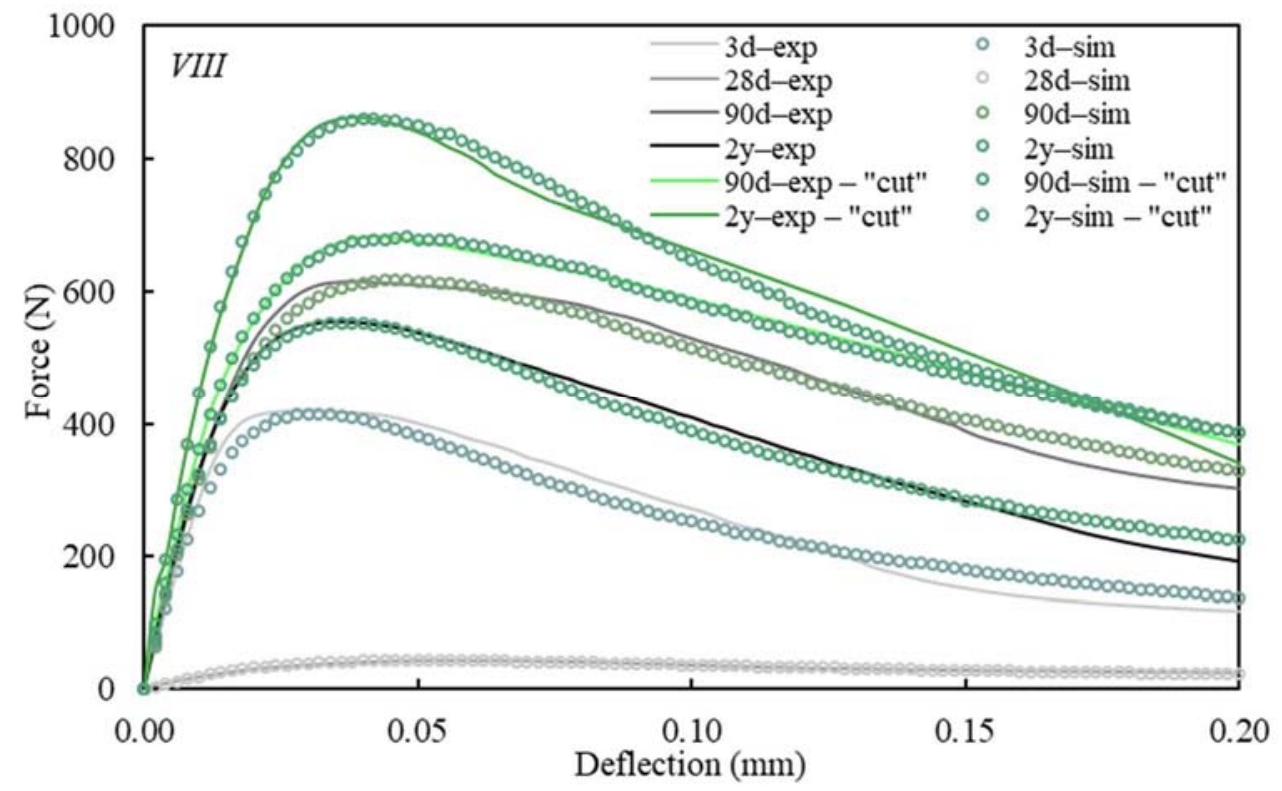

Fig. 6. Comparison of experimentally and numerically obtained $F-d$ diagrams for selected specimens of each set: VIII. 


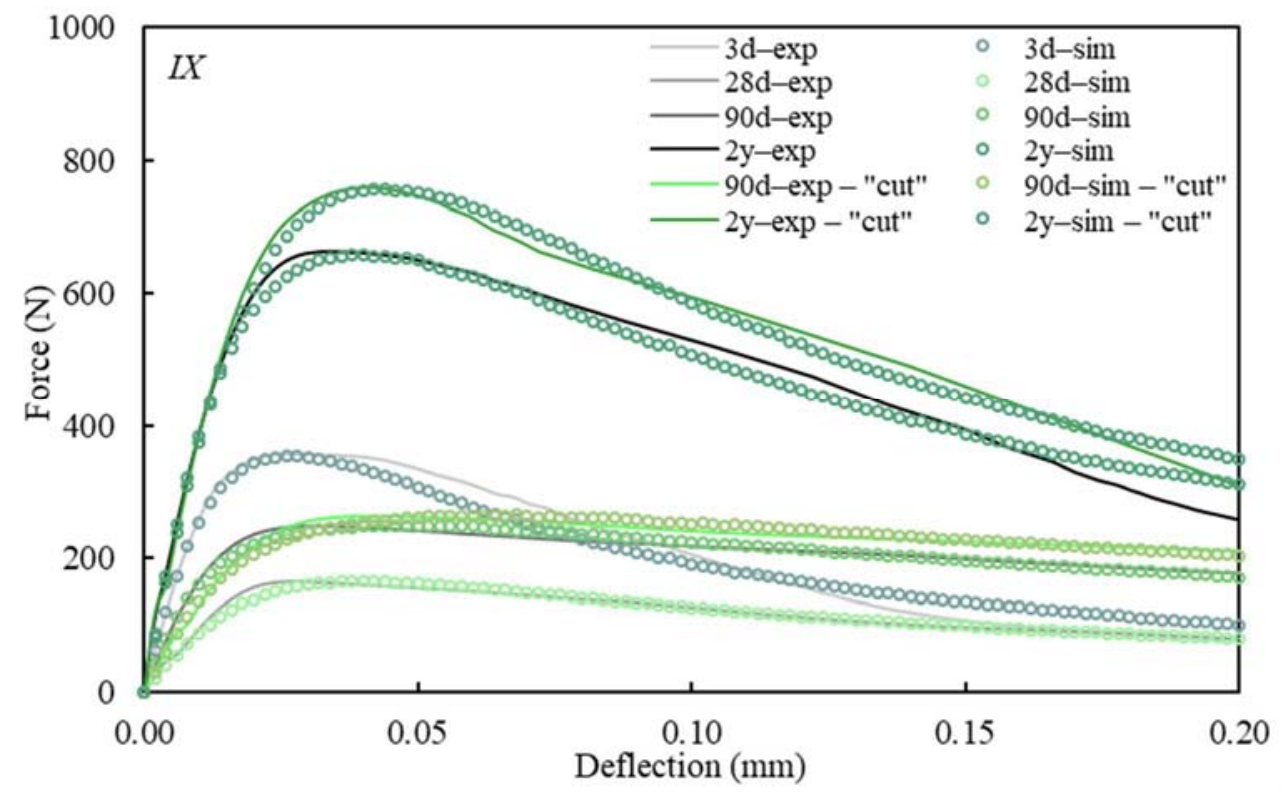

Fig. 7. Comparison of experimentally and numerically obtained $F-d$ diagrams for selected specimens of each set: IX.

\section{Conclusions}

Determination of the mechanical fracture parameters of specimens made of fine-grained composite based on the alkali-activated slag with the addition of shrinkage reducing admixture was carried out at different ages of maturation. The parameters were obtained using two techniques - (i) the direct evaluation of parameters from an experimental $F-d$ diagram by the effective crack model and the work-of-fracture method and (ii) inverse analysis using an artificial neural network-based method. Both techniques provided a comparable trend of development of the monitored parameters during the specimens' ageing. Subsequent verification confirmed the ability of the proposed neural network ensemblebased identification system to identify mechanical fracture parameters of fine-grained brittle matrix composites with variable response while maintaining sufficient accuracy. Obtained values of mechanical fracture parameters can serve efficiently as input data for the stochastic nonlinear simulation of the studied material. In the future, it is planned to extend the identification system with the possibility of taking into account larger deflections than the existing $0.2 \mathrm{~mm}$. This will contribute to a more accurate identification of the specific fracture energy.

This work was supported by projects MUFRAS No. 19-09491S and No. 18-12289Y, awarded by the Czech Science Foundation (GACR) and project No. TF06000016 awarded by Technology agency of the Czech Republic. 


\section{References}

1. H. D. Bui, Inverse Problems in the Mechanics of Materials: An Introduction (CRC Press, 1994).

2. G. E. Stavroulakis, Inverse and Crack Identification Problems in Engineering Mechanics (Springer Science \& Business Media, 2001).

3. D. Novák, D. Lehký, ANN Inverse Analysis Based on Stochastic Small-Sample Training Set Simulation, Eng. Appl. Artif. Intel. 19, (2006).

4. D. Lehký, Z. Keršner, D. Novák, FraMePID-3PB Software for Material Parameters Identification Using Fracture Test and Inverse Analysis, Adv. in Eng. Soft. 72 (2014).

5. D. Lehký, M. Lipowczan, H. Šimonová, Z. Keršner, A neural network ensemble for the identification of mechanical fracture parameters of fine-grained brittle matrix composites, FraMCoS-X 10, (2019).

6. B. L. Karihaloo, Fracture Mechanics and Structural Concrete (Longman Scientific \& Technical, New York, 1995).

7. RILEM TC - 50 FMC (Recommendation), Mater. Struct 18, 4, (1985).

8. V. Červenka, L. Jendele, J. Červenka, ATENA program documentation-Part 1: theory (Cervenka Consulting, Prague, 2016).

9. P. Menétrey, K. J. Willam, Triaxial failure criterion for concrete and its generalization, ACI Structural Journal 92:311-318 (1995).

10. D. A. Hordijk, Local approach to fatigue of concrete, Ph.D. thesis (Delft University of Technology, 1991). 